\title{
Stress and cardiometabolic manifestations among Saudi students entering universities: a cross-sectional observational study
}

\author{
Nasser M Al-Daghri ${ }^{1,2,3^{*}}$, Abdulaziz Al-Othman ${ }^{1,4}$, Omar S Al-Attas ${ }^{1,2,3}$, Khalid M Alkharfy ${ }^{1,2,5}$, Majed S Alokail ${ }^{1,3,4}$, \\ Abdulmajeed Albanyan ${ }^{6}$, Shaun Sabico ${ }^{1,2}$ and George P Chrousos ${ }^{2,7}$
}

\begin{abstract}
Background: In this observational study, we aimed to see whether transition in Saudi students entering university life could be a breeding stage for cardiometabolic risk factor emergence and clustering.

Methods: A total of 1878 apparently healthy Saudi students of the Preparatory Year, King Saud University, Riyadh, KSA (1112 men and 766 women) spanning 2 academic years were included. They were divided into 2 groups based on the validated perceived stress test (PST). Anthropometrics were obtained and fasting blood samples were collected for measurement of fasting blood glucose and a lipid profile.

Results: PST score (>27) considered indicative of stress was noted in $44.4 \%$ of students. The prevalence of this score was higher in women than in men (49.7\% versus $40.7 \%)$. The prevalence of obesity, hypertension and dyslipidemia was significantly higher in men than women $(p<0.01)$, and this was even more apparent among stressed men, who had a significantly higher prevalence of all the above cardiometabolic factors than the non-stressed ones $(p<0.01)$.
\end{abstract}

Conclusion: Perceived stress is alarmingly high among Saudi students entering universities. This study sheds light on the social responsibility of universities in promoting a healthy lifestyle, particularly in this age group, when exposure to different kinds of stressors may result in body weight and metabolic changes.

Keywords: Stress, Cardiometabolic clustering, Saudi, Students, College life, Perceived stress

\section{Background}

Over the last decades, the Kingdom of Saudi Arabia has experienced a great deal of industrialization. This, together with Western influences, brought urbanization and lifestyle change. The impact of these changes is now evident, and its disadvantages abound, specifically its implications in increasing the burden of chronic non-communicable diseases [1]. Obesity is the by-product of the interplay between genetic and environmental factors. In general, overnutrition and sedentary lifestyle are considered two major modifiable risk factors for the progression of both adult

\footnotetext{
* Correspondence: aldaghri2011@gmail.com

'Prince Mutaib Chair for Biomarkers of Osteoporosis, Biochemistry Department, College of Science, King Saud University, P.O. Box, 2455, Riyadh 11451, Kingdom of Saudi Arabia

${ }^{2}$ Biomarkers Research Program, Biochemistry Department, College of Science, King Saud University, Riyadh 11451, Kingdom of Saudi Arabia

Full list of author information is available at the end of the article
}

and childhood obesity. Metabolic syndrome (MetS), which is the clustering of cardiovascular risk factors, including obesity, hypertension, insulin resistance and dyslipidemia, is highly prevalent in both Saudi adults and children [2,3]. While obesity and MetS have been well studied in Saudi Arabia, prevention strategies have been limited. Adolescents and young adults have been largely ignored in most studies, despite the fact they too are exposed to stress, secondary to physical, hormonal, and social transitions.

Stress plays a significant role in the pathogenesis of obesity and MetS [4]. Psychosocial stress among adolescents in particular, is a risk factor for both unhealthy eating and obesity [5]. Students entering the university are vulnerable to weight gain, a phenomenon known as "freshman 15" (or freshman 5 in some) [5]. Studies on weight gain involving young adults in their first year of college have identified certain risk factors, which include,

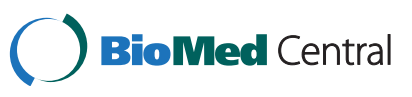


but are not limited to, disordered eating and dietary restraint for women [6], as well as body-building and troublesome relationships with parents for men [7]. Hence, this particular stage in a young adult's life might be a critical developmental window for increased adiposity that requires the involvement of universities in framing prevention programs designed to curtail the weight gain attained by many vulnerable students.

In this study we chose young Saudi adults who are in transition to college life, in an attempt to determine whether sudden environmental changes translate to altered habits that predispose to obesity and other cardiovascular risk factors. To achieve this we will use a well-known tool in assessing global measure of perceived stress that has been used and validated from several studies [8-13]. This study could shed light on the social responsibility of universities and other learning institutions in promoting a healthy lifestyle, particularly in this vulnerable age group, when many transitions, both physical and psychosocial, are happening simultaneously. This study could also help reveal prospectively how this particular population handles stress and whether stress management could diminish cardiovascular risk factor progression.

\section{Methods}

\section{Subjects}

In this cross-sectional study, a total of 1878 apparently healthy Saudi students (1112 men and 766 women for the academic year 2010-2011) were invited to participate. This is a single-center study conducted at the Preparatory Year (PY) College of King Saud University (KSU), Riyadh,
Saudi Arabia. KSU is a state university of KSA with different colleges including PY with almost 35000 students coming all over KSA and neighboring Gulf countries.

\section{Design questionnaire}

Students answered a pre-designed questionnaire that was developed, pre-tested and validated (Table 1). The questionnaire has an internal consistency of 0.85 (Cronbach $\alpha$ co-efficient) and test-retest reliability during a short retest interval (several days) of 0.85 [14]. The questionnaire has several parts including: socio-demographic data, medical history, physical activity, sleep assessment, and a perceived stress test $[13,14]$. Perceived stress test scores are obtained by reversing the scores on four positive items, with a possible range of scores from 0 to 56 [13]. Ethics approval was obtained from the College of Medical Research Center (CMRC), KSU, Riyadh, Saudi Arabia. Written informed consents were required from participants prior to inclusion. Approval from the Dean of the Preparatory Year was also sought prior to commencement of studies.

\section{Inclusion and exclusion criteria}

Only consenting students from the Preparatory Year were included in the study. Students who refused to participate, those with underlying acute and chronic medical conditions that warranted immediate attention (e.g. asthma), and students who were handicapped were excluded from the study.

\section{Anthropometrics}

Weight was recorded to the nearest $0.2 \mathrm{Kg}$ using an international standard scale (Digital Person Scale, ADAM

Table 1 Percentages (\%) of students' responses in the perceived stress test

\begin{tabular}{|c|c|c|c|c|c|}
\hline & Never & Rarely & Sometimes & Usually & Always \\
\hline \multicolumn{6}{|l|}{ In the last month, how often have you... } \\
\hline Been upset because of something that happened unexpectedly? & 5.3 & 11.7 & 47.3 & 27.3 & 8.4 \\
\hline Felt that you were unable to control the important things in your life? & 9.6 & 24.1 & 42.6 & 17.3 & 6.4 \\
\hline Felt nervous and "stressed"? & 5.8 & 19.7 & 40.9 & 25.4 & 8.3 \\
\hline Dealt successfully with irritating life hassles? & 2.7 & 9.0 & 43.5 & 37.3 & 7.6 \\
\hline Felt that you were effectively coping with important changes occurring in your life? & 3.3 & 8.8 & 41.9 & 35.0 & 11.0 \\
\hline Felt confident about your ability to handle your personal problems? & 3.8 & 7.9 & 29.9 & 38.0 & 20.4 \\
\hline Felt that things were going your way? & 4.1 & 13.2 & 48.7 & 27.1 & 7.0 \\
\hline Found that you could not cope with all the things that you had to do? & 13.8 & 29.8 & 41.1 & 12.2 & 3.2 \\
\hline Been able to control irritations in your life? & 4.9 & 17.3 & 46.1 & 24.4 & 7.3 \\
\hline Felt that you were on top of things? & 5.2 & 16.5 & 46.3 & 23.8 & 8.2 \\
\hline Been angered because of things that happened outside of your control? & 4.7 & 16.0 & 42.3 & 26.4 & 10.7 \\
\hline Found yourself thinking about things that you have to accomplish? & 3.2 & 6.0 & 25.0 & 39.2 & 26.6 \\
\hline Been able to control the way you spend your time? & 6.4 & 21.5 & 45.2 & 21.1 & 5.8 \\
\hline Found difficulties were piling up so high that you could not overcome them? & 6.9 & 24.5 & 48.2 & 15.8 & 4.6 \\
\hline
\end{tabular}

Note: Data presented in percentage (\%). 
Equipment Inc., USA); height to the nearest $0.5 \mathrm{~cm}$ using the same scale. BMI was calculated as $\mathrm{kg} / \mathrm{m}^{2}$, and classified as lean, overweight or obese, depending on BMI for age and gender for subjects below 18 years. Waist and hip circumferences were measured by non-stretchable tape measure, and recorded to the nearest $0.1 \mathrm{~cm}$. Body fat composition was also assessed by Body Fat Analyzer (Biospace Inc., USA) to determine body fat percentage, lean mass and fluids distribution. All measurements were administered by well-trained research assistants of the Biomarkers Research Program (BRP) of KSU, Riyadh, KSA.

\section{Biochemical assessment}

Blood was withdrawn in the morning after an overnight fast ( $>10$ hours) and collected in non-heparinized test tubes by an assigned physician. Fasting serum glucose and lipid profile (Total, LDL- and HDL-cholesterol and triglycerides) were measured using routine laboratory procedures (Konelab, Finland). All biochemical estimations and storage of samples were carried out at BRP, KSU, Riyadh, KSA.

\section{Statistical analysis}

Data were analyzed using SPSS 11.5 (Chicago, Illinois) and variables were expressed as mean \pm standard deviation (SD) for continuous variables. Frequencies were presented in percentage (\%). Student t-test was done to compare differences between 2 groups (with and without perceived stress). Bivariate correlations were done to determine associations between perceived stress and metabolic parameters of interest. P-value was considered significant at $<0.05$.

\section{Results}

A total of 1878 preparatory year students participated in this cross-sectional study spanning 2 academic years. Perceived stress was noted in $44.4 \%$ of students $(\mathrm{N}=834$, Table 2). Table 1 shows the percentage distribution of the student responses to the perceived stress test questionnaire, with the majority of responses falling under "sometimes". Comparative analysis was performed among perceived stress versus non-perceived stress group (control) and revealed that those with perceived stress had a significantly higher total cholesterol

Table 2 General characteristics of the subjects studied (Cohort 2010-2011)

\begin{tabular}{|c|c|c|c|}
\hline & Control & Perceived stress & $P$ value \\
\hline $\bar{N}$ & 1044 & 834 & \\
\hline Gender (M/W) & $659 / 385$ & $453 / 381$ & $<0.001$ \\
\hline Age (years) & $18.1 \pm 2.8$ & $18.2 \pm 2.2$ & 0.40 \\
\hline Body mass index (BMI) $\left(\mathrm{kg} / \mathrm{m}^{2}\right)$ & $23.8 \pm 5.4$ & $23.8 \pm 5.9$ & 0.99 \\
\hline Waist circumference (cm) & $80.3 \pm 15.6$ & $79.2 \pm 17.2$ & 0.18 \\
\hline Hip circumference (cm) & $100.1 \pm 14.4$ & $99.8 \pm 14.3$ & 0.62 \\
\hline Sagittal abdominal diameter (SAD) $(\mathrm{cm})$ & $17.6 \pm 6.9$ & $17.3 \pm 7.5$ & 0.45 \\
\hline Total cholesterol $(\mathrm{mmol} / \mathrm{l})$ & $4.2 \pm 0.91$ & $4.4 \pm 0.97$ & 0.03 \\
\hline Glucose $(\mathrm{mmol} / \mathrm{l})$ & $5.1 \pm 0.57$ & $5.2 \pm 0.58$ & 0.64 \\
\hline HDL-cholesterol (mmol/l) & $1.21 \pm 0.32$ & $1.24 \pm 0.32$ & 0.028 \\
\hline Triglycerides (mmol/l) & $0.98 \pm 0.48$ & $0.99 \pm 0.50$ & 0.84 \\
\hline Basal metabolic rate (BMR) & $1644.3 \pm 279.3$ & $1594.8 \pm 280.5$ & 0.001 \\
\hline Arm muscle circumference (AMC) & $21.9 \pm 3.1$ & $21.5 \pm 3.2$ & 0.02 \\
\hline Body cell mass (BCM) & $32.6 \pm 7.5$ & $31.2 \pm 7.5$ & 0.001 \\
\hline Intracellular measured value & $23.4 \pm 5.6$ & $22.4 \pm 5.3$ & $<0.001$ \\
\hline Extracellular measured value & $11.1 \pm 2.5$ & $10.7 \pm 2.4$ & 0.003 \\
\hline Protein mass measured value & $9.3 \pm 2.1$ & $8.9 \pm 2.1$ & 0.001 \\
\hline Mineral mass measured value & $3.1 \pm 0.56$ & $2.9 \pm 0.55$ & $<0.001$ \\
\hline Fat mass measured value & $19.3 \pm 11.4$ & $19.5 \pm 11.8$ & 0.66 \\
\hline Body water & $34.5 \pm 7.7$ & $33.2 \pm 8.0$ & 0.002 \\
\hline Soft lean mass & $43.8 \pm 9.9$ & $42.1 \pm 9.8$ & 0.001 \\
\hline Lean body mass & $46.9 \pm 10.5$ & $45.1 \pm 10.5$ & 0.001 \\
\hline Percent body fat & $27.6 \pm 9.9$ & $28.9 \pm 10.0$ & 0.04 \\
\hline Fat distribution & $0.86 \pm 0.09$ & $0.86 \pm 0.09$ & 0.95 \\
\hline
\end{tabular}

Note: Data presented as mean \pm standard deviation; $\mathrm{p}$-value significant at $\mathrm{p}<0.05$. 
$(p=0.03)$ and body muscle percentage (\%) compared to controls. Furthermore, the perceived stress group had a significantly higher HDL-cholesterol $(p=0.028)$, basal metabolic rate $(\mathrm{BMR})(p=0.001)$, arm muscle circumference (AMC) $(p=0.02)$, body cell mass $(\mathrm{BCM})(p=0.001)$, intracellular $(p=<0.001)$, extracellular $(p=0.003)$, protein $(p=0.001)$ and mineral $(p=<0.001)$ measured values, body water $(p=0.002)$, soft lean mass $(p=0.001)$, and lean body mass $(p=0.001)$ than the controls (Table 2$)$.

To determine whether the differences elicited were influenced by participants' sex, gender stratification was done in both groups (Table 3). No significant differences were elicited in men. In women, however, the perceived stress group had a significantly higher total cholesterol than the controls $(p=0.01)$. The rest of the variables were not significantly different from one another.

Table 4 shows the associations of the different variables measured using the perceived stress scores as a dependent variable. Significant inverse associations, though small, were observed between perceived stress and intracellular $(p=0.001)$ and extracellular $(p=0.001)$ water measured value, as well as soft lean mass $(p=0.008)$. Percent body fat had a small but significant positive association to perceived stress ( $p$-value 0.01). These associations persisted in the stress group while no associations were observed in the non-stressed group (see Table 4).

\section{Discussion}

This study highlights the high level of perceived stress among Saudi students entering pre-college education. The prevalence of high perceived stress, which was noted among $44 \%$ of students, is similar to the ones examined in Egypt and Malaysia [15,16], although these studies utilized medical students as subjects as opposed to the pre-college students in the present study. Comparatively, only total cholesterol was significantly elevated among female students with perceived stress than those without, with no apparent differences observed in male students.

The presence of perceived stress was significantly and inversely associated with several anthropometric parameters in the present study, including fat, mineral and protein values, suggesting modest metabolic alterations at this stage of life. These significant associations have clinical

Table 3 Characteristics of men and women students according to the presence of perceived stress

\begin{tabular}{|c|c|c|c|c|c|c|}
\hline & \multicolumn{3}{|l|}{ Men } & \multicolumn{3}{|l|}{ Women } \\
\hline & Control & Stressed & $P$ value & Control & Stressed & $P$ value \\
\hline $\bar{N}$ & 659 & 453 & & 385 & 381 & \\
\hline Age (years) & $18.4 \pm 2.7$ & $18.4 \pm 2.3$ & 0.65 & $17.8 \pm 2.9$ & $18.1 \pm 2.1$ & 0.18 \\
\hline $\operatorname{BMI}\left(\mathrm{kg} / \mathrm{m}^{2}\right)$ & $24.2 \pm 5.9$ & $24.6 \pm 6.7$ & 0.39 & $23.3 \pm 4.5$ & $23.1 \pm 5.2$ & 0.69 \\
\hline Waist circumference (cm) & $84.7 \pm 16.1$ & $84.1 \pm 19.1$ & 0.62 & $73.1 \pm 11.6$ & $73.5 \pm 12.4$ & 0.66 \\
\hline Hip circumference (cm) & $101.3 \pm 15.9$ & $101.4 \pm 15.4$ & 0.87 & $98.3 \pm 11.4$ & $97.9 \pm 12.5$ & 0.65 \\
\hline $\mathrm{SAD}(\mathrm{cm})$ & $20.0 \pm 6.5$ & $20.3 \pm 8.1$ & 0.47 & $13.3 \pm 5.2$ & $13.4 \pm 4.2$ & 0.82 \\
\hline Total cholesterol (mmol/l) & $4.2 \pm 0.83$ & $4.2 \pm 0.86$ & 0.77 & $4.4 \pm 1.0$ & $4.6 \pm 1.0$ & 0.01 \\
\hline Glucose (mmol/l) & $5.1 \pm 0.61$ & $5.2 \pm 0.60$ & 0.85 & $5.0 \pm 0.49$ & $5.1 \pm 0.56$ & 0.26 \\
\hline $\mathrm{HDL}(\mathrm{mmol} / \mathrm{l})$ & $1.1 \pm 0.25$ & $1.1 \pm 0.25$ & 0.55 & $1.3 \pm 0.36$ & $1.4 \pm 0.32$ & 0.82 \\
\hline Triglycerides (mmol/l) & $1.0 \pm 0.52$ & $1.1 \pm 0.54$ & 0.46 & $0.84 \pm 0.37$ & $0.87 \pm 0.43$ & 0.36 \\
\hline Basal metabolic rate (BMR) & $1808.5 \pm 243.4$ & $1801.5 \pm 250.0$ & 0.70 & $1430.2 \pm 146.7$ & $1420.7 \pm 161.5$ & 0.41 \\
\hline Arm muscle circumference (AMC) & $23.3 \pm 3.1$ & $23.4 \pm 3.3$ & 0.77 & $20.2 \pm 0.9$ & $20.0 \pm 2.1$ & 0.33 \\
\hline Body cell mass (BCM) & $37.1 \pm 6.4$ & $36.7 \pm 6.6$ & 0.51 & $26.7 \pm 3.7$ & $26.5 \pm 4.1$ & 0.55 \\
\hline Intracellular measured value & $26.6 \pm 4.7$ & $26.5 \pm 4.6$ & 0.72 & $19.3 \pm 3.8$ & $18.9 \pm 2.9$ & 0.24 \\
\hline Extracellular measured value & $12.4 \pm 2.2$ & $12.4 \pm 2.3$ & 0.80 & $9.3 \pm 1.3$ & $9.2 \pm 1.4$ & 0.60 \\
\hline Protein mass measured value & $10.7 \pm 1.8$ & $10.6 \pm 1.8$ & 0.65 & $7.6 \pm 1.1$ & $7.5 \pm 1.1$ & 0.48 \\
\hline Mineral mass measured value & $3.4 \pm 0.49$ & $3.3 \pm 0.49$ & 0.46 & $2.6 \pm 0.28$ & $2.6 \pm 0.31$ & 0.43 \\
\hline Fat mass measured value & $19.0 \pm 13.3$ & $19.2 \pm 13.6$ & 0.87 & $19.7 \pm 8.7$ & $19.9 \pm 9.9$ & 0.75 \\
\hline Body water & $39.1 \pm 6.7$ & $39.1 \pm 7.4$ & 0.97 & $28.4 \pm 3.9$ & $28.2 \pm 4.3$ & 0.51 \\
\hline Soft lean mass & $49.8 \pm 8.5$ & $49.5 \pm 8.7$ & 0.63 & $36.1 \pm 5.1$ & $35.9 \pm 5.5$ & 0.55 \\
\hline Lean body mass & $53.2 \pm 9.2$ & $52.9 \pm 9.5$ & 0.70 & $38.7 \pm 5.2$ & $38.5 \pm 5.8$ & 0.67 \\
\hline Percent body fat & $24.0 \pm 9.9$ & $24.1 \pm 10.0$ & 0.96 & $32.3 \pm 7.6$ & $32.4 \pm 8.3$ & 0.78 \\
\hline Fat distribution & $0.87 \pm 0.11$ & $0.87 \pm 0.11$ & 0.96 & $0.85 \pm 0.07$ & $0.85 \pm 0.07$ & 0.57 \\
\hline
\end{tabular}

Note: Data presented as mean \pm standard deviation; $p$-value significant at $p<0.05$. 
Table 4 Associations of different metabolic variables using perceived stress score as a dependent variable

\begin{tabular}{|c|c|c|c|c|c|c|}
\hline & Over a & & Non-str & & Stresse & \\
\hline & $r$ & $p$ & $r$ & $p$ & $r$ & $p$ \\
\hline Age (years) & & & -0.006 & 0.86 & 0.001 & 0.98 \\
\hline $\mathrm{BMI}\left(\mathrm{kg} / \mathrm{m}^{2}\right)$ & 0.01 & 0.60 & 0.02 & 0.45 & 0.02 & 0.50 \\
\hline Waist circumference $(\mathrm{cm})$ & -0.04 & 0.08 & -0.01 & 0.68 & -0.03 & 0.37 \\
\hline Hip circumference $(\mathrm{cm})$ & -0.02 & 0.38 & 0.02 & 0.46 & 0.008 & 0.82 \\
\hline $\mathrm{SAD}(\mathrm{cm})$ & & & -0.008 & 0.80 & -0.07 & 0.05 \\
\hline Total cholesterol $(\mathrm{mmol} / \mathrm{l})$ & 0.06 & 0.01 & 0.01 & 0.65 & 0.04 & 0.25 \\
\hline Glucose (mmol/l) & 0.01 & 0.61 & -0.01 & 0.75 & -0.01 & 0.63 \\
\hline HDL-cholesterol (mmol/l) & 0.05 & 0.03 & -0.01 & 0.65 & 0.03 & 0.48 \\
\hline Triglycerides (mmol/l) & 0.003 & 0.88 & -0.04 & 0.23 & 0.007 & 0.84 \\
\hline Basal metabolic rate (BMR) & -0.04 & 0.07 & 0.01 & 0.66 & -0.03 & 0.38 \\
\hline Arm muscle circumference (AMC) & -0.02 & 0.41 & 0.01 & 0.56 & 0.03 & 0.40 \\
\hline (Body Cell Mass) BCM & -0.04 & 0.08 & 0.01 & 0.63 & -0.04 & 0.25 \\
\hline Intracellular measured value & -0.09 & 0.001 & 0.01 & 0.68 & -0.16 & $<0.001$ \\
\hline Extracellular measured value & -0.09 & 0.001 & 0.009 & 0.79 & -0.15 & $<0.001$ \\
\hline Protein mass measured value & -0.04 & 0.15 & 0.001 & 0.96 & -0.03 & 0.39 \\
\hline Mineral mass measured value & 0.001 & 0.98 & 0.04 & 0.24 & -0.08 & 0.02 \\
\hline Fat mass measured value & 0.01 & 0.51 & 0.03 & 0.43 & -0.03 & 0.32 \\
\hline Body water & -0.06 & 0.01 & 0.01 & 0.67 & -0.17 & $<0.001$ \\
\hline Soft lean mass & -0.07 & 0.008 & 0.001 & 0.97 & -0.11 & 0.005 \\
\hline Lean body mass & -0.01 & -0.61 & 0.02 & 0.61 & -0.05 & 0.23 \\
\hline Percent body fat & 0.06 & 0.01 & 0.03 & 0.41 & 0.05 & 0.17 \\
\hline Fat distribution & 0.02 & 0.37 & 0.02 & 0.51 & 0.02 & 0.63 \\
\hline
\end{tabular}

Note: Data presented as coefficient $(R) ; p$-value significant at $p<0.05$.

implications, despite the fact that the tool used to assess stress is highly subjective and dependent on the individual's personal judgment of how stressed he or she is. It has been well established that stress, both acute and chronic induces a powerful cascade of metabolic and inflammatory processes [17]. How the students in question respond to stress may affect their development and largely predispose to various endocrine, metabolic, autoimmune and psychiatric disorders [18].

The start of college life coincides with emerging adulthood, when young people begin to take control of their own eating and exercise behaviors $[19,20]$. Both the level and duration of stress encountered during this vulnerable period may, thus, further contribute to dysregulation of the stress system, subjecting adolescents to a vicious cycle between distress and distorted self-image, maintaining and worsening distress and associated physiologic and somatic changes [21-23].

We have previously observed that abnormal metabolic patterns among Arabs are highly heritable and can manifest as early as preadolescence [24]. Furthermore, we demonstrated that abnormal sleeping patterns and micronutrient deficiencies such as calcium and vitamin D can increase the likelihood of weight gain in Arab adolescents, a finding also observed in the present study $[25,26]$. These past observations, and the findings of the present study, highlight the importance of chronic disease prevention by targeting the younger population. It is worthy to note that while the Preparatory Year of King Saud University is replete with several physical education classes, its food court is not as health-conscious as it should be. Implementing school-based health promotion that has been proven efficacious in the prevention of childhood obesity [27], therefore, should be taken into consideration.

The strengths of this observational study are that it contributes to the literature in significant ways. First, it takes into account findings from an understudied population from an equally understudied ethnic group. Second, the gender difference elicited in terms of cardiometabolic risk factor prevalence showcase the need for a tailored approach in the prevention of cardiometabolic manifestations in this vulnerable age group. Nevertheless the authors also acknowledge several limitations. The crosssectional and single center approach despite the big sample size limits the causality and generalizability of the study findings. 


\section{Conclusion}

In summary, young Arab adults entering college, who perceive themselves as stressed, are already at increased cardiometabolic risk and this vulnerability appears more prominent in females than males. A follow-up interventional study is needed to validate the present findings and to determine whether stress management and increased coping will translate to an improved cardiometabolic profile among young Arab adults.

\section{Competing interest}

The authors declare that they have no competing interests.

\section{Authors' contributions}

NMA, AA and AMA conceptualized the study. OSA, KMA and MSA participated in interpreting data and in drafting and revising the final manuscript. SS and GPC interpreted data and drafted the final manuscript. All authors read and approved the final manuscript.

\section{Acknowledgments}

This study has been funded by the College of Science Research Center in King Saud University, Riyadh, Saudi Arabia. The authors thank the students of PY and the administration for their support in this study. Special thanks to Mr. Benjamin Vinodson for the analysis of data.

\section{Author details}

${ }^{1}$ Prince Mutaib Chair for Biomarkers of Osteoporosis, Biochemistry Department, College of Science, King Saud University, P.O. Box, 2455, Riyadh 11451, Kingdom of Saudi Arabia. ${ }^{2}$ Biomarkers Research Program, Biochemistry Department, College of Science, King Saud University, Riyadh 11451, Kingdom of Saudi Arabia. ${ }^{3}$ Center of Excellence in Biotechnology Research Center, King Saud University, Riyadh 11451, Saudi Arabia. ${ }^{4}$ College of Applied Medical Sciences, King Saud University, Riyadh 11451, Kingdom of Saudi Arabia. ${ }^{5}$ Clinical Pharmacy Department, College of Pharmacy, King Saud University, Riyadh 11451, Kingdom of Saudi Arabia. ${ }^{6}$ Preparatory Year, King Saud University, Riyadh 11451, Kingdom of Saudi Arabia. ${ }^{7}$ First Department of Pediatrics, Athens University Medical School, Athens 11527, Greece.

Received: 8 October 2013 Accepted: 15 April 2014 Published: 23 April 2014

\section{References}

1. Al-Daghri NM, Al-Attas OS, Alokail MS, Alkharfy KM, Yousef M, Sabico SL, Chrousos GP: Diabetes mellitus Type 2 and other chronic non-communicable diseases in the central region, Saudi Arabia (Riyadh Cohort 2): a decade of an epidemic. BMC Med 2011, 9:76.

2. Al-Daghri NM, Al-Attas OS, Alokail MS, Alkharfy KM, Sabico S, Chrousos GP: Decreasing Prevalence of the full metabolic syndrome but a persistently high prevalence of dyslipidemia among adult Urban Saudis. PLOS ONE 2010, 5:e12159.

3. Al-Daghri NM: High prevalence of metabolic syndrome manifestations among Arab youth: a call for early intervention. Eur J Clin Invest 2010, 40:1063-1066.

4. Chrousos GP: The role of stress and the hypothalamic-pituitary-adrenal axis in the pathogenesis of the metabolic syndrome: neuroendocrine and target-tissue-related causes. Int J Obes Relat Metab Disord 2000, 24:S50-S55.

5. Crombie AP, Illich JZ, Dutton GR, Panton LB, Abood DA: The freshman weight gain phenomenon revisited. Nutr Rev 2009, 67:83-94.

6. Delinsky SS, Wilson GT: Weight gain, dietary restraint, and disordered eating in the freshman year of college. Eat Behav 2008, 9:82-90.

7. Holm-Denoma JM, Joiner TE, Vohs KD, Heatherton TF: The "freshman fifteen" (the "freshman five" actually): predictors and possible explanations. Health Psychol 2008, 27:53-59.

8. Andreou E, Alexopoulos EC, Leonis C, Varvogli L, Gnardellis C, Chrousos GP, Darviri C: Perceived stress scale: reliability and validity in Greece. Int J Environ Res Public Health 2011, 8:3287-3298.
9. Katsarou A, Panagiotakos D, Zafeiropoulou A, Vryonis M, Skoularigis I, Tryposkiadis F, Papageorgiou C: Validation of a Greek version of PSS-14; a global measure of perceived stress. Cent Eur J Public Health 2012, 20:104-109.

10. Luft CD, Sanches Sde O, Mazo GZ, Andrade A: Brazilian version of the perceived stress scale: translation and validation for the elderly. Rev Saude Publica 2007, 41:606-615.

11. Barbosa-Leiker C, Kostick M, Lei M, McPherson S, Roper V, Hoekstra T, Wright $B$ : Measurement invariance of the perceived stress scale and latent mean differences across gender and time. Stress Health 2012, :11. Epub ahead of print

12. Aggarwal NT, Clark CJ, Beck TL, de Leon CF M, Decarli C, Evans DA, Everson Rose SA: Perceived stress is associated with subclinical cerebrovascular disease in older adults. Am J Geriatr Psychiatry 2013, Epub ahead of print.

13. Bougea AM, Spandideas N, Alexopoulos EC, Thomaides T, Chrousos GP, Darviri C: Effect of the emotional freedom technique on perceived stress, quality of life, and cortisol salivary levels in tension-type headache sufferes: a randomized-controlled trial. Explore (NY) 2013, 9:91-99.

14. Cohen S, Kamarck T, Mermelstein R: A global measure of perceived stress. $J$ Health Soc Behav 1983, 24:385-396.

15. El-Gilany $\mathrm{AH}, \mathrm{Amr} \mathrm{M}$, Hammad S: Perceived stress among male medical students in Egypt and Saudi Arabia: effect of sociodemographic factors. Ann Saudi Med 2008, 28:442-448.

16. Sherina MS, Rampal L, Kaneson N: Psychological stress among undergraduate students. Med J Malaysia 2004, 59:207-211.

17. Chrousos GP: Stress and disorders of the stress system. Nat Rev Endocrinol 2009, 5:374-381.

18. Charmandari E, Achermann JC, Carel JC, Soder O, Chrousos GP: Stress response and child health. Sci Signal 2012, 5:mr1. doi:10.1126/scisignal.2003595.

19. Gillen MM, Lefkowitz ES: The 'freshman 15': trends and predictors in a sample of multiethnic men and women. Eat Behav 2011, 12:261-266.

20. Morgan AZ, Keiley MK, Ryan AE, Radomski JG, Gropper SS, Connell LJ, Simmons KP, Ulrich PV: Eating regulation styles, appearance schemas, and body satisfaction predict changes in body fat for emerging adulthood. I Youth Adolesc 2012, 41:1127-1141.

21. Pervanidou P, Chrousos GP: Stress and obesity/metabolic syndrome in childhood and adolescence. Int J Pediatr Obes 2011, Suppl 1:21-28.

22. Morin $\mathrm{KH}$ : Starting college: a critical time for weight gain. MCN Am J Matern Child Nurs 2012, 37:130.

23. Martyn-Nemeth P, Penckofer S, Gulanick M, Velsor-Friedrich B, Bryant FB: The relationships among self-esteem, stress, coping, eating behavior, and depressive mood in adolescents. Res Nurs Health 2009, 32:96-109.

24. Al-Daghri NM, Al-Attas OS, Alokail MS, Alkharfy KM, Yakout SM, Sabico SB, Gibson GC, Chrousos GP, Kumar S: Parent-offspring transmission of adipocytokine levels and their associations with metabolic traits. PLOS ONE 2011, 6:e18182.

25. Al-Disi D, Al-Daghri N, Khanam L, Al-Othman A, Al-Saif M, Sabico S, Chrousos G: Subjective sleep duration and quality influence diet composition and circulating adipocytokines and ghrelin levels in teen-age girls. Endocr $J$ 2010, 57:915-923.

26. Al-Musharaf S, Al-Othman A, Al-Daghri NM, Krishnaswamy S, Yusuf DS, Alkharfy KM, Al-Saleh Y, Al-Attas OS, Alokail MS, Moharram O, Yakout S, Sabico S, Chrousos GP: Vitamin D deficiency and calcium intake in reference to increased body mass index in children and adolescents. Eur J Pediatr 2012, 171:1081-1086.

27. Fung C, Kuhle S, Lu C, Purcell M, Schwartz M, Storey K, Veuglers PJ: From "best practice" to "next practice": the effectiveness of school-based health promotion in improving healthy eating and physical activity and preventing childhood obesity. Int J Behav Nutr Physical Act 2012, 9:27.

doi:10.1186/1471-2458-14-391

Cite this article as: Al-Daghri et al:: Stress and cardiometabolic manifestations among Saudi students entering universities: a cross-sectional observational study. BMC Public Health 2014 14:391. 